\title{
A Screening Platform for Compounds with Potential Immuno-regulatory Activities Using Human Cord Blood Mononuclear Cells
}

\author{
Chia-Jung Chen ${ }^{1}$, Chia Che Tsai ${ }^{1}$, Jung-Feng Hsieh ${ }^{2}$, Chichen Michael Chien ${ }^{3}$ Tzu-Hua $\mathrm{Wu}^{4}$ and \\ Shui-Tein Chen ${ }^{1,2^{*}}$
}

\author{
${ }^{1}$ Institute of Biochemical Sciences, National Taiwan University, Taipei, Taiwan \\ ${ }^{2}$ Institute of Biological Chemistry \& Genomic Research Center, Academia Sinica, Taipei, Taiwan \\ ${ }^{3}$ Department of Obstetrics and Gynecology, Ton-Yen General Hospital, Hsinchu, Taiwan \\ ${ }^{4}$ Department of Clinical Pharmacy, School of Pharmacy, College of Pharmacy, Taipei Medical University, Taipei, Tai- \\ wan
}

\begin{abstract}
A systematic and combinatorial approach was adopted using human umbilical cord blood mononuclear cells (hUCB-MNCs) to screen for potential immuno-regulatory compounds. The hUCB-MNCs contain several types of immunogenic cells, which are a suitable material to mimic the in vivo immuno-response after drug treatment. hUCB-MNCs were treated with various natural products such as quercetin, astaxanthin, caffeic acid, bilobalide, eugenol, rutin and $\gamma$ dodecalactone ( $\gamma$-DDL). Phenotypic expression analysis revealed that the subpopulation of $\mathrm{CD}^{+} \mathrm{T}$ cells, $\mathrm{CD}^{+} 6^{+} \mathrm{NK}$ cells and $\mathrm{CD}_{1} \mathrm{a}^{+}$dendritic cells apparently increased after being treated with $\gamma$-DDL for 6 days. The expression of CD56 reached a maximum at $72 \mathrm{~h}$ with a dose-dependent relationship. The NK cells activation marker (CD69) also elevated following $\gamma$-DDL treatment. These results demonstrated that the $\gamma$-DDL has immuno-regulatory effects to enhance cord blood NK cells population and bioactivities. Such a high-throughput methodology using hUCB-MNCs may be an effective platform for systematically screening potential immuno-regulatory compounds.
\end{abstract}

Keywords: High-throughput screening, human umbilical cord blood mononuclear cells, natural products, flow cytometry, immuno-regulatory activities, $\gamma$-dodecalactone.

\section{INTRODUCTION}

Mankind has utilized natural remedies to enhance immunity for thousands of years [1]. Many significantly defined fractions or compounds of natural products have been proven to modulate immunological functions. Moreover, immunological cells can also be directly regulated by such fractions or compounds [2]. Various plants or herbs like Ganoderma lucidum, Vitis vinifera, Triticum aestivum and Antrodia camphorata often cover a broad spectrum of biological activities [3-6]. The polysaccharides of Ganoderma lucidum have been shown to modulate the cell immunophenotypic expression of various CD markers and enhance CD56 ${ }^{+}$ NK-cell cytotoxicity in human cord blood mononuclear cells (hUCB-MNCs) [7]. Some natural compounds, such as astaxanthin, quercetin or rutin have been reported to have antioxidant and other biological activities: such as antiinflammatory or anti-tumor activity [8-11]. However, the biological activities of many natural products including $\gamma$ dodecalactone $(\gamma$-DDL) have not yet been investigated. The goal of this study was to develop an effective platform for analyzing immuno-regulatory activity among natural products.

High-throughput screening bioassay platforms like the proposed assay for immuno-regulatory activity of natural products can benefit a broad spectrum of applications from

*Address correspondence to this author at theInstitute of Biological Chemistry, Academia Sinica, Room 707, No. 128, Sec. 2, Yen Chiu Yuan Road, Nankang District, Taipei 115, Taiwan; Fax: 886-2-27883473;

E-mail: bcchen@gate.sinica.edu.tw drugs to new materials [12]. Success in finding a biologically active molecule using a combinatorial approach is proportional to the number of molecules subjected to the screening process. However, a systematic procedure with efficacy and effectiveness for screening drugs in modulating human immune functions has not yet been available. Hence, the aim of this study is to establish a high-throughput screening platform for identifying natural components with potential immuno-regulatory activities using MNCs isolated from hUCB. The MNCs collected from hUCB comprise immature lymphocytes, which can be differentiated into different subsets of immune cells, due to their progenitor properties. The hUCB-MNCs are excellent candidates for studying the maturation and promoting functions of natural products stimulated immune cells.

Flow cytometry is a useful tool for identifying and characterizing various tagged cellular constituents such as those involved in the cell cycle, protein expression or apoptosis [13]. Cell type differentiation and maturation can be observed by flow cytometry via specific fluorescently labeled monoclonal antibodies to detect the cluster of differentiation (CD) markers of hUCB-MNCs. The CD markers used in this study for combinatorial characterization of antigens for the immuno-phenotyping of immune cells are listed in Table $\mathbf{1}$.

\section{MATERIALS AND METHODS}

\section{Materials}

Human umbilical cord blood (hUCB), RPMI culture medium (consisting of 90\% RPMI-1640, 2 mM L-glutamine, 
Table 1. The CD Markers Used in the Characterization of Cell Surface Antigens for Immuno-Phenotyping

\begin{tabular}{|c|c|}
\hline Cell Types & Cd Marker \\
\hline \hline T Lymphocyte & CD3 \\
\hline Monocyte/Macrophage & CD14 \\
\hline B Lymphocyte & CD19 \\
\hline Hematopoietic Stem Cell & CD34 \\
\hline Leukocyte & CD45 \\
\hline NK Cell & CD56 \\
\hline Dendritic Cell & CD83, CD1a \\
\hline
\end{tabular}

$4.5 \mathrm{~g} / \mathrm{L}$ glucose, $10 \mathrm{mM}$ HEPES, $1.5 \mathrm{~g} / \mathrm{L}$ sodium bicarbonate, $1 \mathrm{mM}$ sodium pyruvate, $100 \mathrm{units} / \mathrm{mL}$ penicillin, 100 $\mu \mathrm{g} / \mathrm{mL}$ streptomycin, $0.25 \mu \mathrm{g} / \mathrm{mL}$ amphotericin, $10 \%$ fetal bovine serum (FBS), Dulbecco's phosphate buffered saline (PBS, pH 7.5), and the natural products (100 $\mu \mathrm{M}$ each) quercetin, astaxanthin, caffeic acid, bilobalide, eugenol, rutin and $\gamma$-dodecalactone $(\gamma$-DDL) were purchased from Sigma. Biocoll separating solution (density 1.077) was obtained from Autogenbioclear. The specific antibodies CD3, T cell receptor; CD14, monocyte/macrophage; CD19, B cell; CD34, hematopoietic stem cell; CD45, leukocyte; CD56, natural killer cell; CD83 and CDla, dendritic cell; and CD69, FITC, were purchased from Serotec. NK cells magnetic beads (MACS) were purchased from Miltenyi Biotec. Finally, WST-1 reagent (4-[3-(4-lodophenyl-2-(4-nitrophenyl)-2H-5tetrazolio)-1, 3-benzene disulfonate and IL-2 (500 U/mL) were obtained from Roche

\section{Methods}

\subsection{Isolation of hUCB Mononuclear Cells}

The hUCB from healthy volunteers was drawn into EDTA-coated tubes. Blood was collected immediately after a full-term baby was delivered and before the placenta was separated from the uterus. Using aseptic procedures, an 18gauge needle was inserted into the umbilical vein and umbilical cord blood drawn for tests. Samples were stored at room temperature and processed within $24 \mathrm{~h}$ after collection. The hUCB $(100 \mathrm{~mL})$ was processed using density gradient centrifugation with equal volume of Biocoll separating solution without breaking. Centrifugation for $30 \mathrm{~min}$ at $1900 \mathrm{rpm}$ $(300 \mathrm{~g})$ was carried out using a swinging-bucket rotor to isolate the mononuclear cell layer in the interphase. The buffy coat interface was obtained, and the cells were washed twice with PBS and centrifuged for $5 \mathrm{~min}$ at $1500 \mathrm{rpm}$ at room temperature. The cells were re-suspended in RPMI culture medium. Mononuclear cells isolated through these procedures were prepared at a final concentration of $10^{6}$ cells $/ \mathrm{mL}$.

\subsection{Measuring the hUCB Phenotypic Changes by Flow Cytometric Analysis}

The MNCs isolated from the hUCB specimens were placed in culture flasks at $10^{6}$ cells $/ \mathrm{mL}$ density for the preparation of natural compounds treatment. After seeding of cells, the flasks were maintained at $37^{\circ} \mathrm{C}$ in a $5 \% \mathrm{CO}_{2}$ incubator for $24 \mathrm{~h}$ to equilibrate. Then, the natural products were added to each culture, and an equal volume of PBS was added to control cultures. After 6 days, the cells were pelleted and re-suspended in $3 \mathrm{~mL}$ of PBS. PBS buffer $(100 \mu \mathrm{L})$ containing fluorescence-conjugated antibody $(10 \mu \mathrm{L})$ was added to each cell suspension for labeling in preparation for flow cytometry. After incubation at $4{ }^{\circ} \mathrm{C}$ for $40 \mathrm{~min}$, all samples were then centrifuged at $1500 \mathrm{rpm}$ for $5 \mathrm{~min}$, followed by washing of the pellets twice with PBS. The suspension was removed and cold PBS $(0.2 \mathrm{~mL})$ at $4^{\circ} \mathrm{C}$ was added. Each monoclonal antibody, including CD3, CD14, CD19, CD34, CD45, CD56, CD83 and CD1a, was used to label the surface antigens of immune cells.

\subsection{Determination of Cell Proliferation by WST Assay}

Cell proliferation was measured by reducing activity using the WST assay. Briefly, $4 \times 10^{3}$ cells/well $(100 \mu \mathrm{L})$ were incubated for $48 \mathrm{~h}$, and then the WST-1 reagent was added $(10 \mu \mathrm{L} / w e l l)$, followed by incubatation for $4 \mathrm{~h}$ at $37^{\circ} \mathrm{C}$ in $5 \%$ $\mathrm{CO}_{2}$. Absorbance was measured with a spectrophotometer using test and reference wavelengths of 450 and $630 \mathrm{~nm}$, respectively. Each experiment was performed in triplicate and repeated at least three times. Results were expressed as the mean \pm SEM.

\subsection{Isolation of NK Cells from hUCB-MNCs by MACS Beats Method}

$\mathrm{CD} 6^{+} \mathrm{NK}-\mathrm{cells}$ isolated from hUCB-MNCs were enriched by using a negative magnetic beads cell separation method. The hUCB-MNCs pellet was resuspended in $40 \mu \mathrm{L}$ buffer per $10^{7}$ total cells. Biotin-antibody cocktail $(10 \mu \mathrm{L}$ per $10^{7}$ total cells) was added and the cells were incubated for 10 $\min$ at $4 \sim 8^{\circ} \mathrm{C}$. Buffer and anti-biotin microbeads $(30 \mu \mathrm{L}$ and $20 \mu \mathrm{L}$, respectively, per $10^{7}$ total cells) were added, followed by incubation for $15 \mathrm{~min}$ at $48^{\circ} \mathrm{C}$. Cells were washed with buffer by adding 10-20x labeling volume followed by centrifugation at $1500 \mathrm{rpm}$ for $10 \mathrm{~min}$. The supernatants were removed completely, and the cells were resuspended in buffer $(50 \mu \mathrm{L}$ each). The column was prepared by rinsing with $3 \mathrm{~mL}$ buffer. The cell suspension was applied to the column and washed with buffer $(3 \times 3 \mathrm{~mL})$. Aliquots of the sorted cells were stained by FITC-labeled anti-CD56 ${ }^{+}$ monoclonal antibody to analyze the purity of $\mathrm{CD}^{+} 6^{+} \mathrm{NK}$ cells. The purity of the isolated NK-cells was determined by flow cytometric analysis and reached up to $70-95 \%$.

\subsection{Activation of NK Cells by Flow Cytometric Analysis of CD56 and CD69}

Highly enriched $\mathrm{CD}^{+} 6^{+} \mathrm{NK}$-cell suspensions were cultured in a medium supplemented with RPMI-1640, and four different concentrations $(100,250,500 \mu \mathrm{M}$ and $1 \mathrm{mM})$ of $\gamma$ DDL, were added into cell suspensions. The control group was treated with PBS. After 24, 36, 48 and $72 \mathrm{~h}$ of incubation, the cultures were washed twice with PBS and then labeled with CD56-FITC antibody to analyze CD56 marker expression of NK cells. Next, CD69-FITC antibody was also used to detect CD69 marker expression of NK cells after treating with $\gamma$-DDL $(100,250,375$, or $500 \mu \mathrm{M})$ for $24 \mathrm{~h}$ followed by flow cytometric analysis.

\section{RESULTS AND DISCUSSION}

Seven natural products astaxanthin, caffeic acid, bilobalide, eugenol, rutin, quercetin and $\gamma$-DDL, were screened for 
Table 2. The Structure, Molecular Weight and Previously Published Functions of the Seven Natural Compounds Used for Screening ( $\gamma$-Dodecalactone)

\begin{tabular}{|c|c|c|l|}
\hline Compounds & $\begin{array}{c}\text { Molecular } \\
\text { weight }\end{array}$ & \multicolumn{1}{c|}{ Functions } \\
\hline Qustaxanthin & $\mathbf{5 9 6 . 8 4}$ & Unknown \\
\hline Caffeic acid & 180.16 & Antioxidant, anti-inflammatory, anti-tumor, \\
anti-allergic, lower-cholesterol (9, 11, 17-19)
\end{tabular}

their potential immuno-function. The structures and known functions of these compounds are shown in Table 2. These six compounds inhibit the common function of providing relief from oxidative stress [8, 10, 11, 14-16]. Furthermore, astaxanthin is also reported to lower-cholesterol and have posses anti-inflammatory, anti-tumor, and anti-allergic activities [9, 17-19]; bilobalide has a neuroprotective effect [24]; whereas eugenol, caffeic acid, rutin, and quercetin have anti-inflammatory, anticarcinogenic, and antithrombotic functions [26-30]. $\gamma$-DDL is a volatile organic compound that is widely distributed in fruits and herbs [31]. No biological functions of $\gamma$-DDL have been reported. In our previous research, $\gamma$-DDL was isolated and identified from the essential oil of $A$. camphorata by gas chromatography (GC) analysis (data not shown).

We used hUCB-MNCs as a mixture of immuno-cells that could be stimulated by the natural products during incubation, together in cell culture media. The CD marker changes were measured as immuno-cell maturation or activation using flow cytometric analysis. The distributions of the monocytes in hUCB-MNCs are shown in Fig. 1.

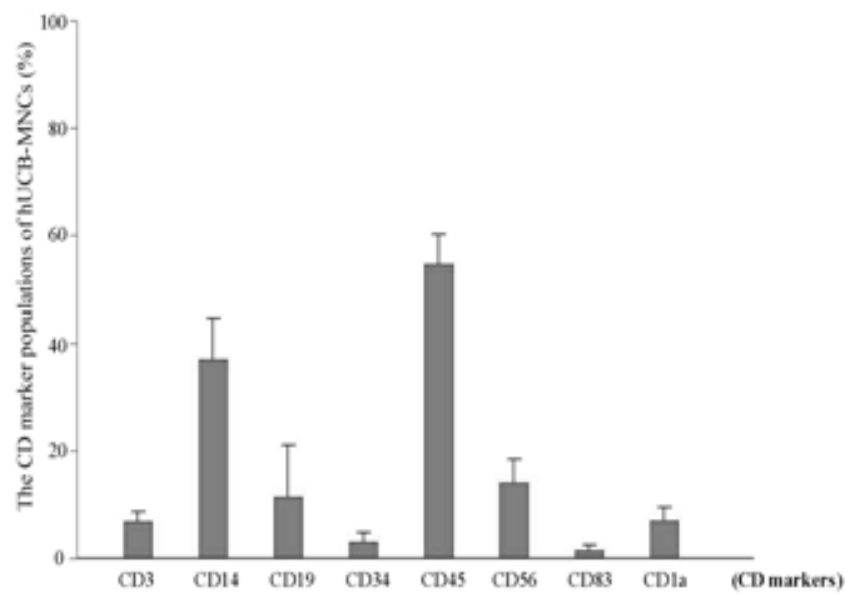

Fig. (1). Detection of hUCB-MNCs phenotypic expression by flow cytometric analysis. Flow cytometric analysis of $\mathrm{CD} 3$, T cell; CD14, monocyte/macrophage; CD19, B cell; CD34, hematopoietic stem cell; CD45, leukocyte; CD56, natural killer cell; CD83 and CDla, dendritic cell. These experiments were repeated three times to five times with similar results. Results are expressed as the mean \pm S.E.M. 


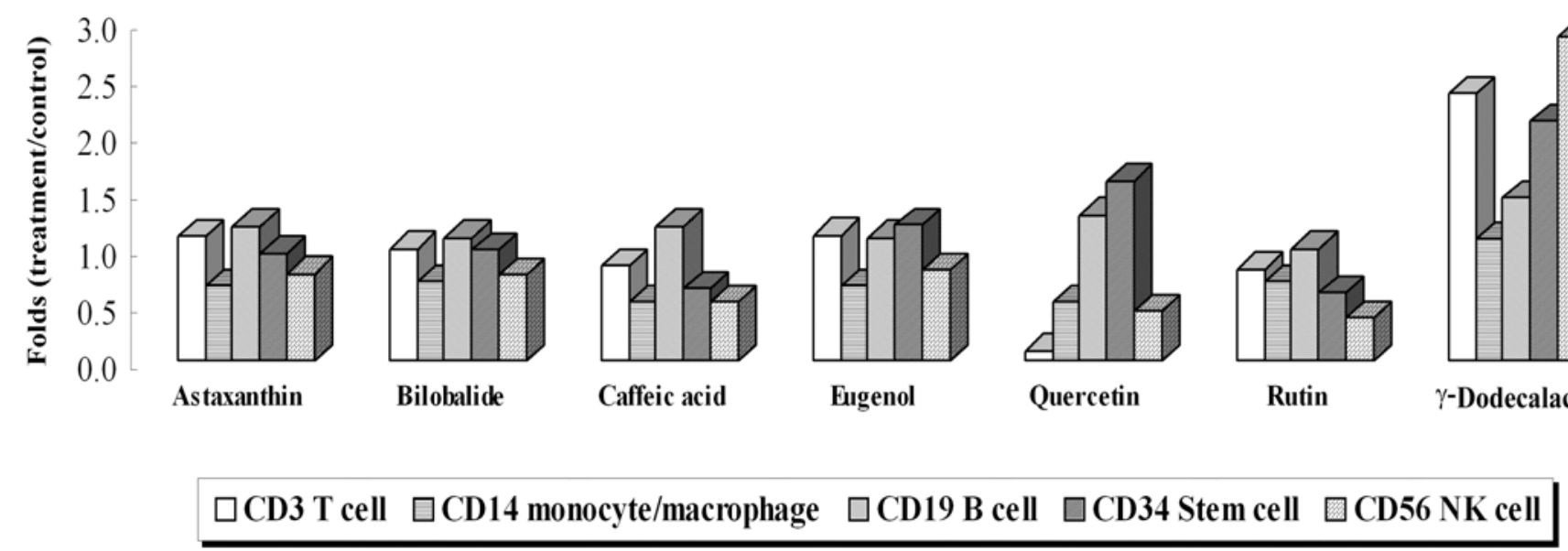

Fig. (2). Detection of hUCB phenotypic changes after treatment with natural compounds using the flow cytometry assay. The hUCBMNCs were incubated for $24 \mathrm{~h}$ to equilibrate and then treated with natural compounds $(100 \mu \mathrm{M}$ each of astaxanthin, bilobalide, caffeic acid, quercetin, eugenol, rutin, or $\gamma$-DDL). Controls were treated with an equal volume of PBS instead of a natural product. The expression of CD3 T cells, CD14 monocyte/macrophages, CD19 B cells, CD34 hematopoietic stem cells, CD56, and natural killer cells in the hUCBMNCs were detected using flow cytometry after natural compound treatment for 6 days. Results are expressed as a ratio of expression to the control.

After treating hUCB-MNCs with astaxanthin, caffeic acid, bilobalide, eugenol and rutin, the populations of $\mathrm{T}$ cells, monocyte/macrophage, B cells, hematopoietic stem cells, and natural killer cells showed no significant change. However, one exception was quercetin, which reduced the CD3 expression of T cells and induced CD34 expression of stem cells. Thus, quercetin produced different stimulatory effects in diverse immune cells as compared to other natural products. When treating hUCB-MNCs with $\gamma$-DDL, the populations of CD3 $\mathrm{T}$ cells and CD56 NK cells were increased over 2.5 fold (Fig. 2). The integral immunophenotypic changes of hUCB-MNCs after $\gamma$-DDL treatment, and the overexpressions of CD3 T cells, CD56 natural killer cells and CDla dendritic cells among the hUCB-MNCs population are shown in Fig. 3. Therefore, it was shoen that $\gamma$-DDL can alter cell immunophenotypic expression in hUCB-MNCs, but is not harmful to the cell, since the cell numbers of the hUCB-MNCs decreased slightly both in control and $\gamma$-DDL treatment groups for 6 days (Fig. 4).

The observation that $\gamma$-DDL can induce overexpression of CD56 in the hUCB-MNCs mixture is interesting. CD56 ${ }^{+}$ NK cells have been known to represent a highly specialized lymphoid population characterized by a potent cytolytic activity against tumor or virally infected cells [32]. Compared to healthy controls, the cytotoxicity of NK cells decreases in peripheral blood of patients with various types of cancer [33].

The dose dependence of CD marker expression in hUCBMNCs was then investigated to further understand the immuno-regulatory function of $\gamma$-DDL. The results showed that CD56 expression increased by 52.99, 53.22, 68.68, 94.94, and $97.34 \%$ in hUCB-MNCs when treated with $0 \mu \mathrm{M}, 100$ $\mu \mathrm{M}, 250 \mu \mathrm{M}, 500 \mu \mathrm{M}$ and $1 \mathrm{mM} \gamma$-DDL, respectively. CD56 expression increased gradually and almost reached a maximum level at $500 \mu \mathrm{M}$ after $\gamma$-DDL treatment (Fig. 5A). The CD56 marker of hUCB-NK cells was analyzed for timedependent expression following $\gamma$-DDL treatment $(100 \mu \mathrm{M})$. Fig. 5B shows that the expression level of CD56 progressively increased up to $48 \mathrm{~h}$ and diminished at $72 \mathrm{~h}$.
IL-2 can stimulate and activate NK cells to show cytotoxicity and simultaneous expression of CD69 as a membrane marker during the activation [34]. Thus, CD69 is a marker of NK cells activation. We also detected an increased level of CD69 expression in hUCB-NK cells after treating with $\gamma$ DDL for $24 \mathrm{~h}$. For comparing the relative stimulating activities of IL-2 and $\gamma$-DDL induced NK cells expression of CD69, four different concentrations of $\gamma$-DDL (100-500 $\mu \mathrm{M})$ and IL-2 $(500 \mathrm{U} / \mathrm{mL})$ were incubated with hUCB-NK cells respectively for $24 \mathrm{~h} \mathrm{(35).} \mathrm{We} \mathrm{found} \mathrm{the} \mathrm{expression} \mathrm{level} \mathrm{of}$ CD69 to be increased in the following ranges $39.35,49.30$, 58.71 , and $61.68 \%$ following NK cells activation with various concentrations $(100,250,375$, and $500 \mu \mathrm{M})$ of $\gamma$-DDL, respectively. (Fig. 6A). The CD69 expression level of hUCB-NK cells treated with $\gamma$-DDL $(>250 \mu \mathrm{M})$ reached 1.5 times higher than the untreated control (Fig. 6B). These findings suggest that $\gamma$-DDL has immuno-regulatory activities that enhanced the hUCB-NK cells population.

\section{CONCLUSIONS}

The hUCB-MNCs were found to be an excellent candidate for studying the maturation-promoting function of natural products since the immune cells of blood from newborns were almost without external stimulation. It was essential to amplify the screening assay so that it became sensitive enough to measure the stimulation activities of natural products. As a result, this platform could be effectively and systematically applied in screening potential immuno-regulatory compounds. In particular, $\gamma$-DDL was involved in the activation of hUCB-NK cells and showed potential immunoregulatory activities.

In conclusion, flow cytometry measurement can be a good method for the screening of immune cell mixtures to find stimulated immune cells. Combining flow cytometry with the screening of natural product libraries we have established a high-throughput method for the discovery of immuno-regulatory compounds using mixed hUCB-MNCs, including different immune cells that can mimic in vivo conditions. 
A
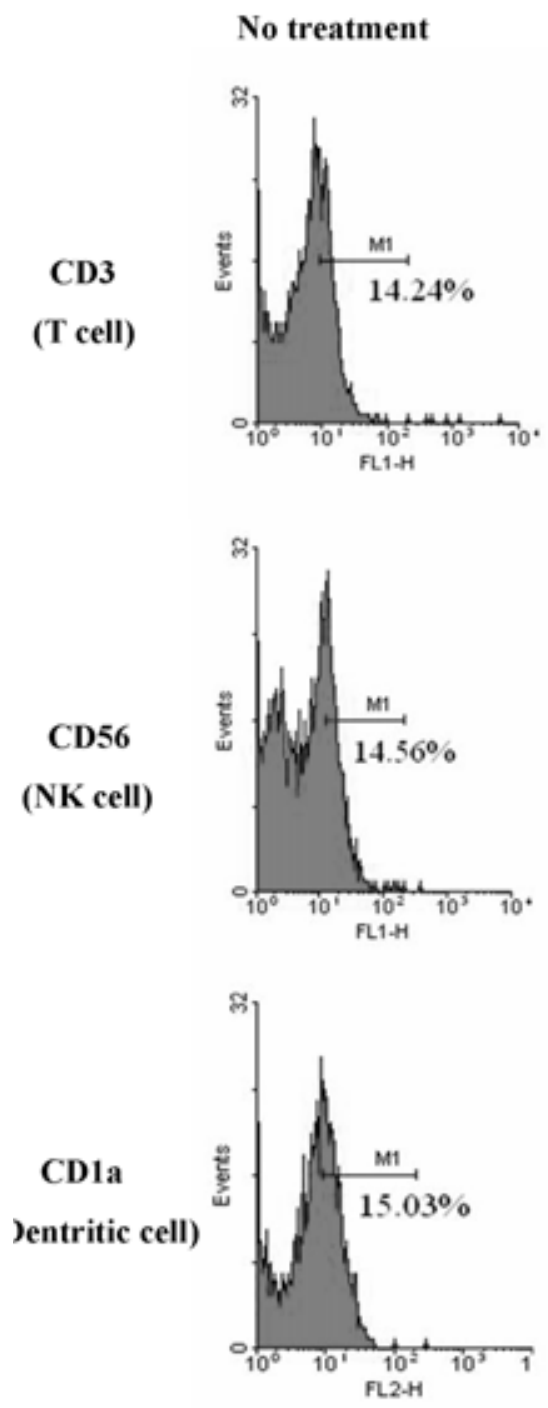

$100 \mu \mathrm{M} \gamma$-dodecalactone
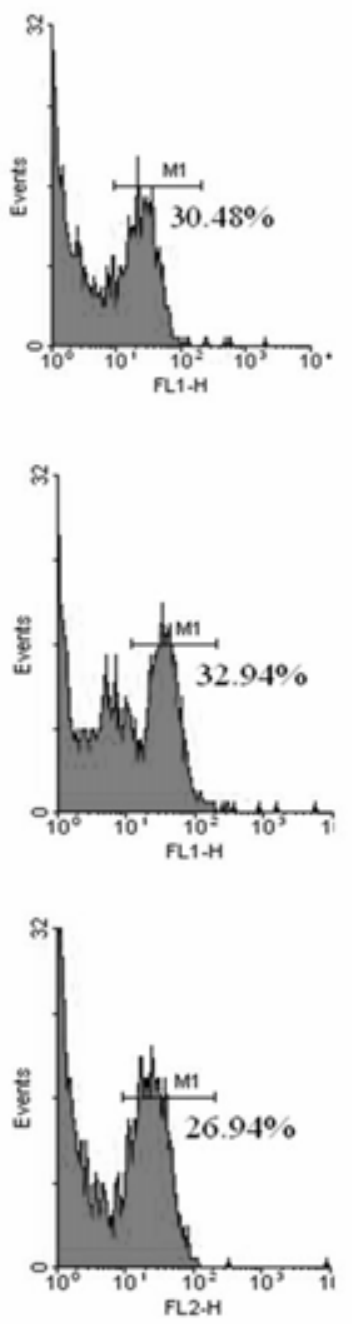

Merge (\% of increase)
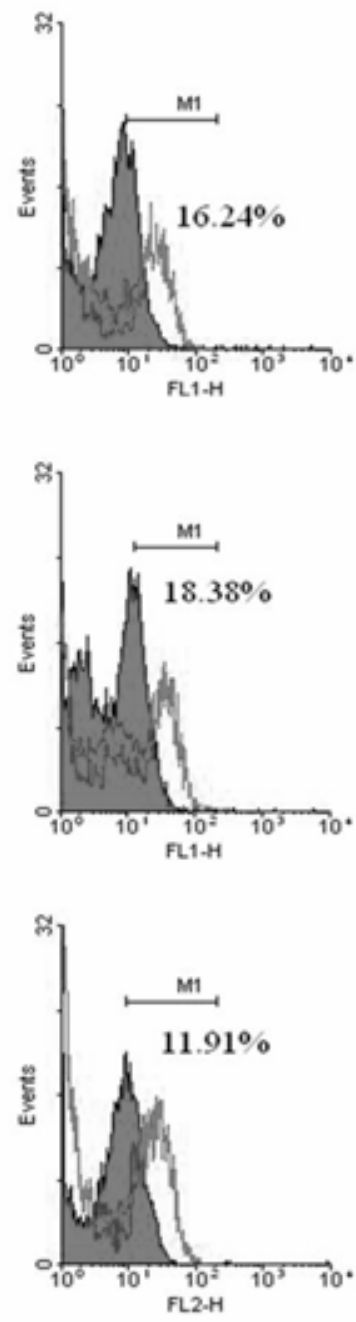

B

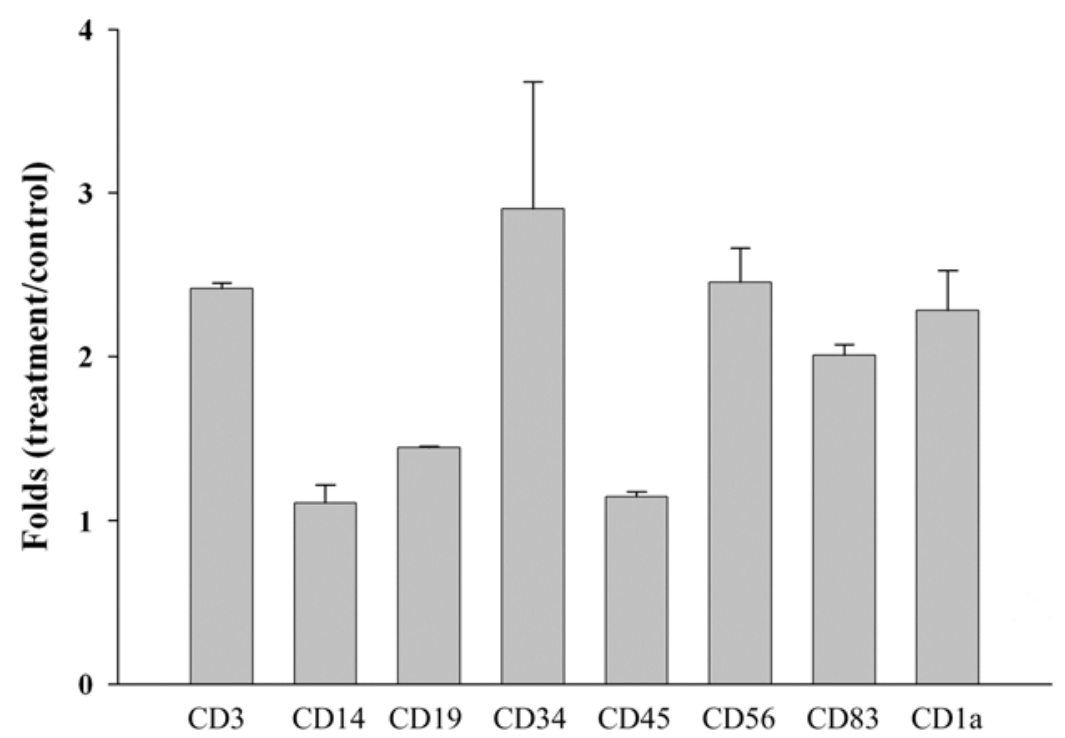

Fig. (3). Detection of hUCB phenotypic changes after treatment with $\boldsymbol{\gamma}$-dodecalactone using the flow cytometry assay. (A) The expression of CD3 T cells, CD56 natural killer cells and CDla dendritic cells on the hUCB-MNCs population after treatment with $\gamma$-DDL (100 $\mu \mathrm{M}$ ) measured using flow cytometry. (B) The ratio of CD3, CD14, CD19, CD45, CD56, CD83, and CD1a expression in hUCB-MNCs was measured after $\gamma$-DDL treatment for 6 days compared to control. Each experiment was performed in triplicate and repeated at least three times. Results are expressed as the mean \pm SEM. 


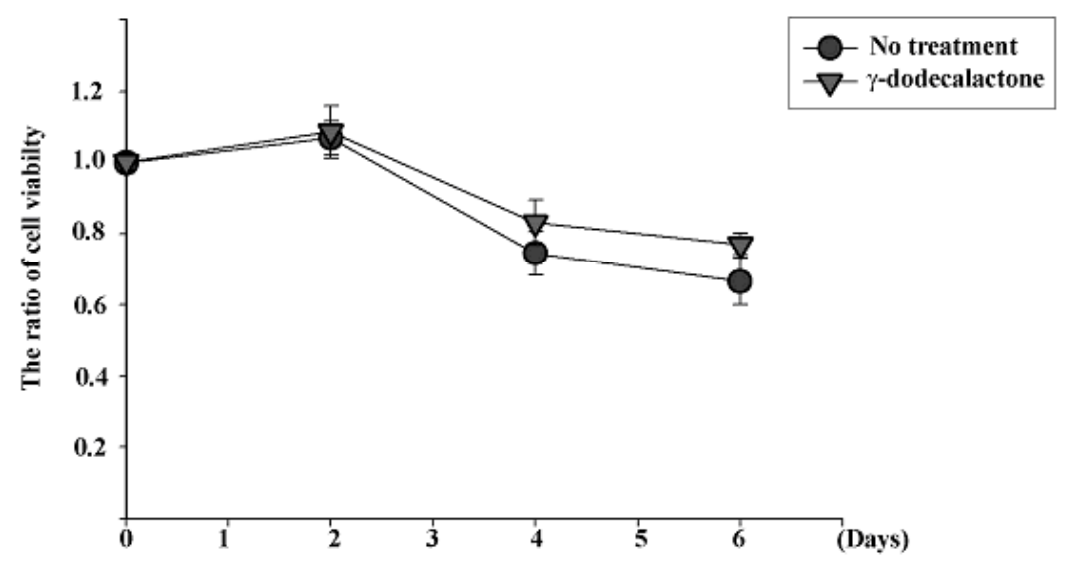

Fig. (4). Detection of hUCB-MNCs proliferation by the WST assay. hUCB-MNCs were incubated for $24 \mathrm{~h}$ to equilibrate, $\gamma$-DDL (100 $\mu \mathrm{M})$ was added to each culture, and then the cells were incubated for 6 days. Control cultures were identical except that an equal volume of PBS was added instead of $\gamma$-DDL. The cell proliferation was analyzed based on the time course (each 2 days) after $\gamma$-DDL treatment. For analysis, WST-1 reagent was added, the cells were incubated for $4 \mathrm{~h}$ at $37^{\circ} \mathrm{C}$, and then the absorbance was measured absorbance at the test and reference wavelengths of 450 and $630 \mathrm{~nm}$, respectively.

A

No treatment (control)

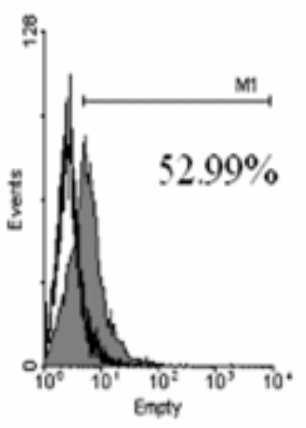

B

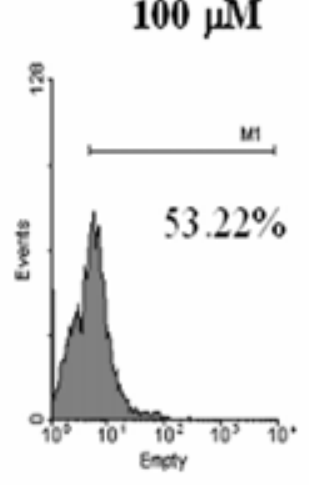

$250 \mu \mathrm{M}$

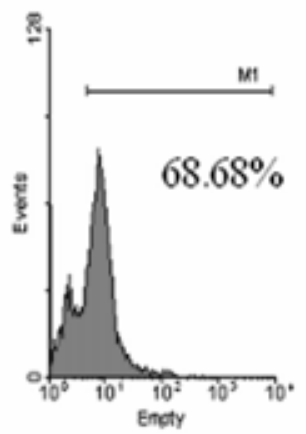

భ-dodecalactone

$500 \mu \mathrm{M}$

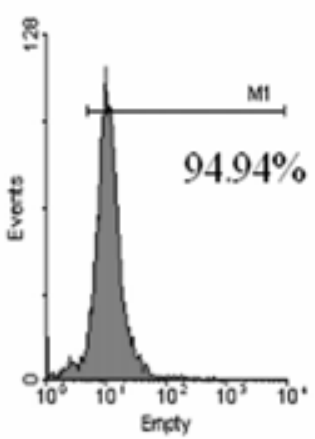

$1 \mathrm{mM}$

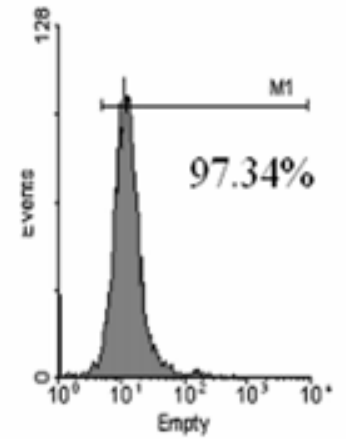

$24 \mathrm{~h}$

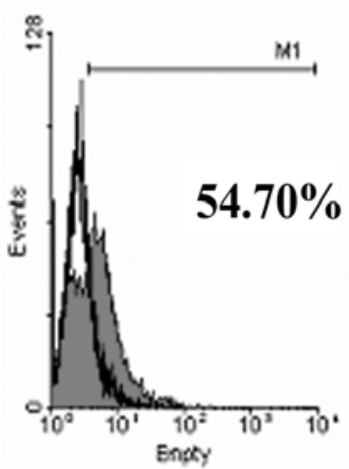

$36 \mathrm{~h}$

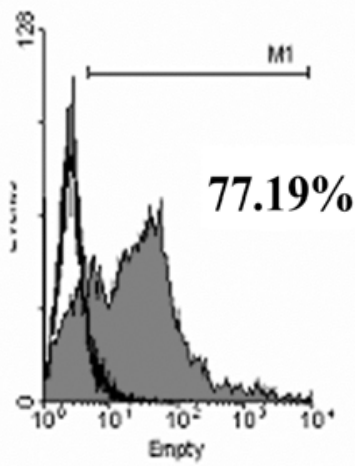

$48 \mathrm{~h}$

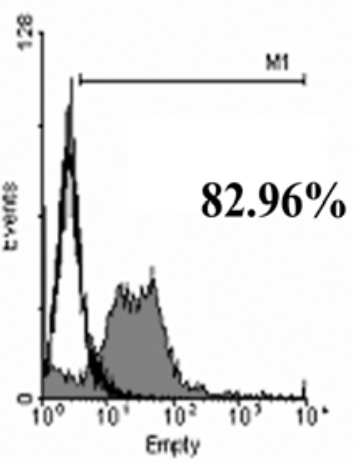

$72 \mathrm{~h}$

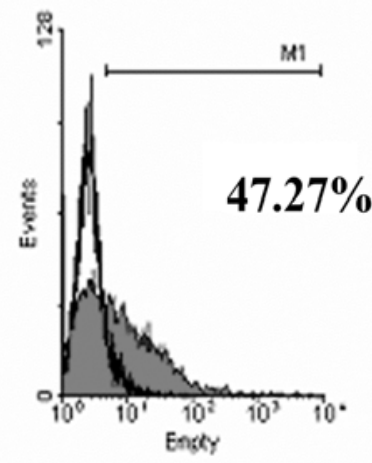

Fig. (5). Detection of the CD56 marker activation in hUCB-NK cells treated with $\boldsymbol{\gamma}$-DDL. (A) After enrichment of CD56 hUCB-NK cells from hUCB-MNCs by magnetic separation, hUCB-NK cells were incubated with four different doses of $\gamma$-DDL (100, $250,500 \mu \mathrm{M}$, or $1 \mathrm{mM}$ ) for $24 \mathrm{~h}$ followed by flow cytometric analysis. (B) Detection of the CD56 marker of hUCB-NK cells by time-dependent expression $(24,36,48$, and $72 \mathrm{~h})$ with $\gamma$-DDL $(100 \mu \mathrm{M})$ treatment. 
A

No treatment

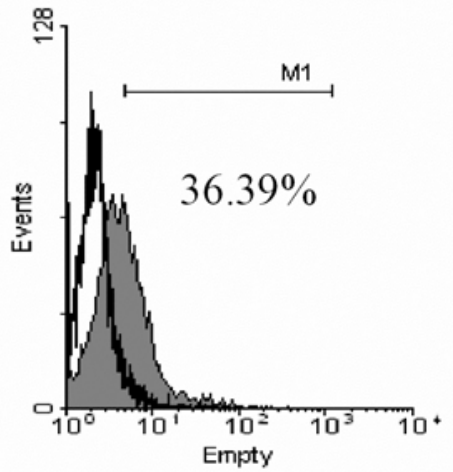

$250 \mu \mathrm{M}$ $\gamma$-dodecalactone

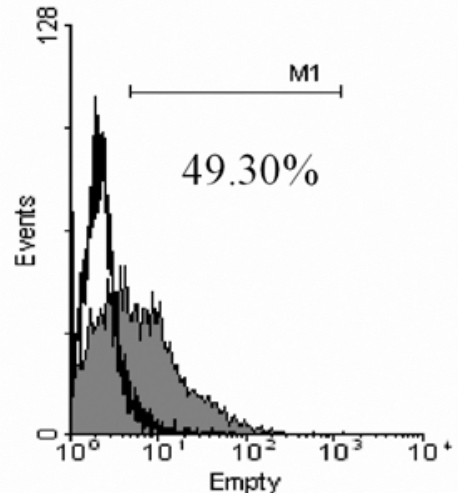

$500 \mathrm{U} / \mathrm{mL}$

IL-2

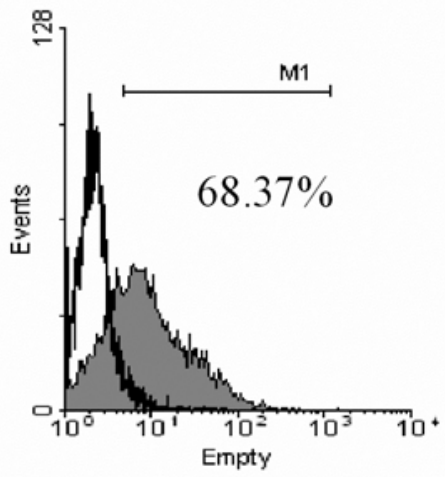

$375 \mu \mathrm{M}$

$\gamma$-dodecalactone

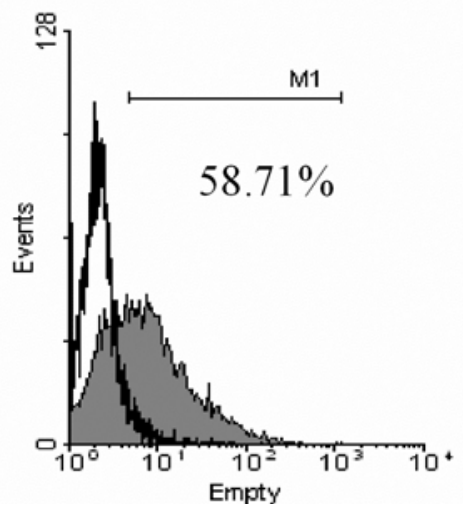

$100 \mu \mathrm{M}$

$\gamma$-dodecalactone

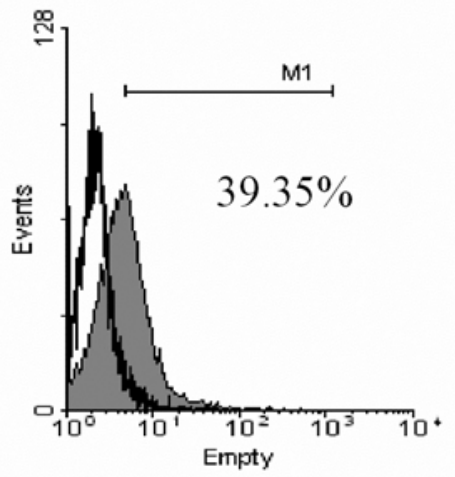

$500 \mu \mathrm{M}$

$\gamma$-dodecalactone

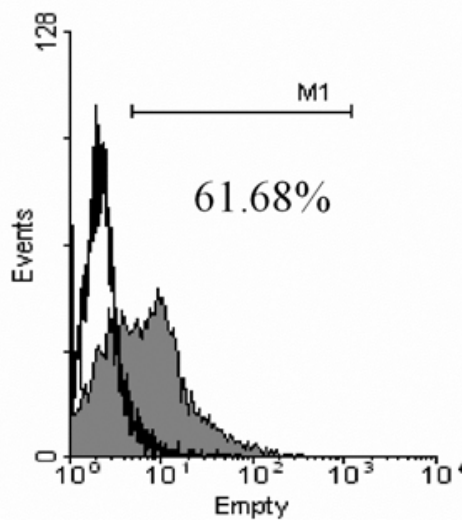

B

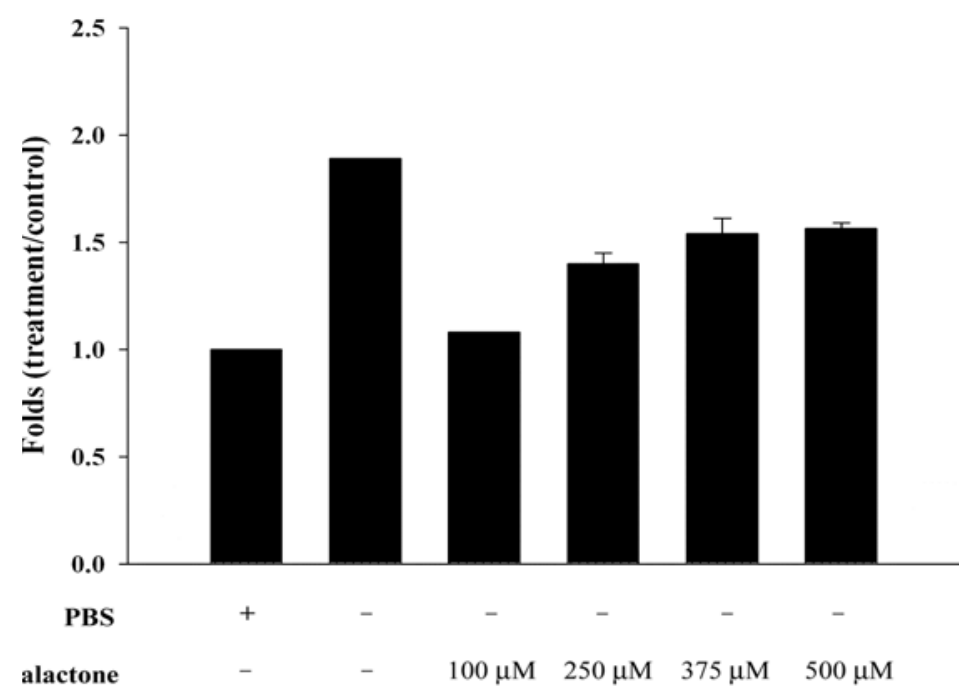

IL-2

$500 \mathrm{U} / \mathrm{mL}$

Fig. (6). Detection of the CD69 marker activation in hUCB-NK cells treated with $\boldsymbol{\gamma}$-DDL. (A) The CD69 expression of hUCB-NK cells was detected by using flow cytometric analysis after treatment of the cells with four different concentrations of $\gamma$-DDL (100, 250, 375, and $500 \mu \mathrm{M})$ or IL-2 $(500 \mathrm{U} / \mathrm{mL}$, a positive control) for $24 \mathrm{~h}$. (B) The ratio of CD69 expression in hUCB-NK cells was determined after treatment with four concentrations of $\gamma$-DDL for 6 days compared to the controls. The experiments (but not the positive control) were repeated three times. Results are expressed as the mean \pm S.E.M. 


\section{ACKNOWLEDGEMENTS}

Support for this research is gratefully acknowledged from the National Science Council, Taiwan, and the Thematic Research Project of Academia Sinica, Taiwan.

\section{ABBREVIATIONS}

$$
\begin{array}{ll}
\mathrm{CD} & =\text { Cluster of differentiation } \\
\mathrm{GC} & =\text { Gas chromatography } \\
\mathrm{FBS} & =\text { Fetal bovine serum } \\
\gamma \text {-DDL } & =\gamma \text {-dodecalactone } \\
\text { hUCB } & =\text { Human umbilical cord blood } \\
\mathrm{IL} & =\text { Interleukin } \\
\text { MACS } & =\text { Magnetic cell sorting } \\
\text { MNCs } & =\text { Mononuclear cells } \\
\text { NK } & =\text { Natural killer } \\
\text { PBS } & =\text { Phosphate buffered saline } \\
\text { REFERENCES }
\end{array}
$$

\section{REFERENCES}

[1] Lien, E.J. Prog. Drug Res., 1990, 34, 395-420.

[2] Cao, L.Z.; Lin, Z.B. Immunol. Lett., 2002, 83, 163-9.

[3] Chen, H.S.; Tsai, Y.F.; Lin, S.; Lin, C.C.; Khoo, K.H.; Lin, C.H.; Wong, C.H. Bioorg. Med. Chem., 2004, 12, 5595-601.

[4] Khanna. S.; Roy, S.; Bagchi, D.; Bagchi, M.; Sen, C.K. Free Radic. Biol. Med., 2001, 31, 38-42.

[5] Kulkarni, S.D.; Tilak, J.C.; Acharya, R.; Rajurkar, N.S.; Devasagayam, T.P.; Reddy, A.V. Phytother. Res., 2006, 20, 218-27.

[6] Lee, I.H.; Huang, R.L.; Chen, C.T.; Chen, H.C.; Hsu, W.C.; Lu, M.K. FEMS Microbiol. Lett., 2002, 209, 63-7.

[7] Chien, C.M.; Cheng, J.L.; Chang, W.T.; Tien, M.H.; Tsao, C.M.; Chang, Y.H.; Chang, H.Y.; Hsieh, J.F.; Wong, C.H.; Chen, S.T. Bioorg. Med. Chem., 2004, 12, 5603-9

[8] Guardia, T.; Rotelli, A.E.; Juarez, A.O.; Pelzer, L.E. Farmaco, 2001, 56, 683-687.

[9] Lamson DW; Brignall MS. Alt Med Rev, 2000, 5, 196-208.

[10] Deschner, E.E.; Ruperto, J.F.; Wong, G.Y.; Newmark, H.L. Nutr. Cancer, 1993, 20, 199-204.

[11] Wu, T.H.; Liao, J.H.; Hou, W.C.; Huang, F.Y.; Maher, T.J.; Hu, C.C. J. Agric. Food Chem., 2006, 54, 2418-23.
[12] Elswijk, D.A. van; Irth, H. Phytochem. Rev., 2003, 1, 427-439.

[13] Perez, O.D.; Nolan, G.P. Immunol. Rev., 2006, 210, 208-28.

[14] Hussein, G.; Sankawa, U.; Goto, H.; Matsumoto, K.; Watanabe, H. J. Nat. Prod., 2006, 69, 443-9.

[15] Jung, U.J.; Lee, M.K.; Park, Y.B.; Jeon, S.M.; Choi, M.S. J. Pharmacol. Exp. Ther., 2006, 318, 476-83.

[16] Fujisawa, S.; Atsumi, T.; Kadoma, Y.; Sakagami, H. Toxicology, 2002, 177, 39-54.

[17] Lee, E.; Choi, E.J.; Cheong, H.; Kim, Y.R.; Ryu, S.Y.; Kim, K.M. Arch. Pharm. Res.,, 1999, 22, 320-323.

[18] Kurowska, E.M.; Spence, J.D.; Jordan, J.; Wetmore, S.; Freeman, D.J.; Piche, L.A.; Serratore, P. Am. J. Clin. Nutr., 2000, 72, 10951100 .

[19] Hollman, P.C.; Van Trijp, J.M.; Mengelers, M.J.; De Vries, J.H.; Katan, M.B. Cancer Lett., 1997, 114, 139-140.

[20] Hussein, G.; Sankawa, U.; Goto, H.; Matsumoto, K.; Watanabe, H. J. Nat. Prod., 2006, 69, 443-9.

[21] Jung, U.J.; Lee, M.K,; Park, Y.B,; Jeon, S.M,; Choi, M.S. J. Pharmacol. Exp. Ther., 2006, 318, 476-83.

[22] da Cunha, F.M.; Duma, D.; Assreuy, J.; Buzzi, F.C.; Niero, R.; Campos, M.M.; Calixto, J.B. Free Radic. Res., 2004, 38, 1241-53.

[23] Huang, S.H.; Duke, R.K.; Chebib, M.; Sasaki, K.; Wada, K.; Johnston, G.A. Neuroscience, 2006, 137, 607-17.

[24] Chen, Y.S.; Liu, C.J.; Cheng, C.Y.; Yao, C.H. Biomaterials, 2004, 25, 509-14.

[25] Fujisawa, S.; Atsumi, T.; Kadoma, Y.; Sakagami, H. Toxicology,, 2002, 177, 39-54.

[26] Li, W.; Tsubouchi, R.; Qiao, S.; Haneda, M.; Murakami, K.; Yoshino, M Biomed. Res., 2006, 27, 69-74.

[27] Kostyuk, V.A.; Potapovich, A.I. Arch. Biochem. Biophys., 1998 $355,43-48$.

[28] Kostyuk, V.A.; Potapovich, A.I.; Speransky, S.D.; Maslova, G.T. Free Rad. Biol. Med., 1996, 21, 487-493.

[29] Drewa, G.; Schachtschabel, D.O.; Palgan, K., et al. Neoplasma, 1998, 45, 266-271

[30] Schmitt, A.; Savayre, R.; Delchambre, J.; Negre-Salvayre, A. Br. J. Pharmacol., 1995, 116, 1985-1990.

[31] Valim, M.F.; Rouseff, R.L.; Lin, J. J. Agric. Food Chem., 2003, 51, 1010-5.

[32] Moretta, L.; Moretta, A. EMBO J.,, 2004, 23, 255-259.

[33] Warren, H.S.; Christiansen, F.T.; Witt, C.S. Br. J. Haematol., 2003 , 121,793 .

[34] Borrego, F.; Robertson, M.J.; Ritz, J.; Pena, J.; Solana, R. Immunology, 1999, 97, 159-165.

[35] Maino, V.C.; Suni, M.A.; Ruitenberg, J.J. Cytometry, 1995, 20, $127-133$. 